\title{
MULTILINGUAL AND MULTICULTURAL REASONING IN THE JUDGMENTS OF THE COURT OF JUSTICE OF THE EUROPEAN UNION
}

\author{
LAIMDOTA LOČMELE
}

University of Latvia, Latvia

\begin{abstract}
This paper aims to analyse selected judgments made by the Court of Justice of the European Union (CJEU). In order to perceive a judgment, it is necessary to interpret its text and understand the reasoning. While the Court ensures the uniform interpretation and application of the European Union (EU) law in all member states, the working language of the Court is French. Multilingualism is achieved with the help of translations of texts into all official languages of the EU. Multiple translations from one language into another affect the form and the content of judgments and make them formulaic and difficult to read. The present study applies discourse analysis to study the judgments and focus on their narrative form - the syntactic and semantic macrostructures of the judgments in order to answer the question if macrostructures facilitate or hinder the communication process in the multilingual situation where there is no universal language to be used in official discourse in the EU. It is found that although the narrative structure of the CJEU judgments is specific and not familiar to non-specialist readers and students of law, it is a tool for valid interpretation of judgments.
\end{abstract}

Key words: multilingualism, judgments of the CJEU, syntactic and semantic macro-structures, legal reasoning, linguistic interpretation

\section{INTRODUCTION}

The judgments of the Court of Justice of the European Union (CJEU) make a significant part of the ever-growing body of European law, which is obvious to anyone who visits EUR-Lex - the official website of the EU law. Research of legal texts on legal reasoning and interpretation falls within the classification of comparative legal studies, for example, Koskinen (2000), Komarek (2015). The aspects of the language of EU legislative texts are discussed in a number of articles - Campos-Pardillos (2010), Šarčevic (2010), Bengoetxea (2011), Breeze (2013), Paunio (2013). The theoretical sources selected for this study have originated from empirical research because many authors whose work has 
been used as the basis for this study have been present at the CJEU drafting and translating legal texts - McAuliffe (2010, 2011a, 2011b, 2012, 2013), Robertson (2014), McAuliffe and Trklja (2018). Researchers acknowledge that the role of 'narrative in law has rarely received the attention that it deserves' (Breeze, 2013: 343). Besides, there has not been enough research into the role of language in the production of case law (McAuliffe, 2011b: 492).

For this study, the most significant theoretical sources on interpretation and structure of judgments are Bengoetxea (2011), McAuliffe (2011a, 2011b), and McAuliffe and Trklja (2018). In the present paper, the CJEU judgments are viewed as a specific type of narrative. Therefore, the other part of the theoretical basis of this paper is the narrative theory and discourse analysis, the study on narrative macro-structures by Van Dijk $(1976,1985)$ and Labov $(2010)$. The goal of the paper is to explore the narrative structure of the CJEU judgments, to identify the structural elements and their relationships in judgments, as well as to find out the impact of this structure on the interpretation of the judgments. For this purpose, the following tasks have to be completed: reading of the judgments in order to identify the semantic and syntactic macro-structures and the analysis of the macrostructures to describe their mutual relationship and their specific place and meaning in the whole judgment.

\section{THEORETICAL BACKGROUND}

In Europe, a universal language 'which everyone might, or ought to, speak' has always been needed (Eco, 1997: 73). It may be argued that the EU needs a universal legal language in its current situation with 24 official languages forming 'unity through diversity' (Online 1).

The EU multilingualism is divided into three categories: the original languages of the Treaties, the official languages of the EU and the working languages of the EU where each institution may create its own internal rules on working languages (Online 2). In the EU, to organise the work in a manageable way, translation of documents is carried out directly from one language into another and, since 2004, through pivot languages (French, English, German, Spanish and Italian) (McAuliffe and Trklja, 2018: 14).

The CJEU applies the principle of the language of the case, which means that the case may come before the Court in any language of the EU. Then it is translated into French, the working language of the Court; internal reports, the opinion, the judgment, the secret deliberations, and the final judgment are drafted in French. The final authentic judgment is a translation from French into the language of the case (Online 3). The text of a judgment is drafted, redrafted and translated several times, and the exact equivalence between different texts remains a fiction 'due to the nature of natural languages' (Paunio, 2013: 11). The authentic version of the decision, for instance, in Kik v OHIM (the Office for Harmonization in the Internal Market) (Judgment 4) is not in the original because it was drafted in French, not Dutch, which is the language 
of the case. Thus, the authenticity of the document and the originality of the language in which it was drafted almost always diverge. In such a way, translation serves as proof of linguistic equality rather than conveying a message or facilitating communication (Koskinen, 2000: 83). For example, in EMU Tabac (EMU Tobacco SARL, company name) (Judgment 4) the Court says: 'all the language versions must, in principle, be recognised as having the same weight'. Translation to reach the equality of these texts leads to their hybridity and linguistic precedent (McAuliffe, 2011b: 492). EU legal documents are considered to be 'hybrid texts because of the unique manner in which they are created' (McAuliffe, 2011b: 99). In addition to the fact that these judgments are drafted in French by legal assistants who are mostly not French native speakers, there are language and style rules that the legal assistants are obliged to follow. Besides, the secret deliberations leading to compromise among the judges make the texts of judgments formulaic, abstract and unclear. There exists an opinion that the 'Court French' in which the case law is produced affects the case law itself and 'inevitably leads to a type of linguistic precedent' (ibid.: 485).

Despite the equal value of the official language versions in judicial interpretation, equivalence is sometimes reduced to mere 'visual equivalence' (Paunio, 2013: 8). The language versions look identical; the number of paragraphs has to match, and the headings and subheadings have to be located in the same place as in other language versions (ibid.). Equivalence, therefore, is symbolic and leads to the idea that translation of EU legislation is not intended to communicate a message to a particular interlocutor, but rather to produce law (ibid.).

Not any of the EU languages is the universal language, but all of them together have developed an official mixed and hybrid variant of Euro-language with specifically moulded structures and new words in each official language.

The CJEU, therefore, aims to produce statements of law that will have the same effect throughout all EU member states, in every language in which they are published, and through such statements to ensure the uniform application of EU law. So the CJEU considers that there is one "communicative system" within the EU, albeit expressed in 24 linguistic forms, across 28 different legal cultures. (McAuliffe, 2015: 9)

This communicative system is the universal language, or rather a supra linguistic semiotic system capable of carrying out the functions of universal language.

The CJEU is the institution involved in reconciling differing language versions and clarifying the language issues in different languages through legal reasoning - 'a particular form of discourse used in the interpretation and application of the law' (Bengoetxea, 2011: 103). Legal scholars who are concerned with comparative law distinguish four methods of interpretation: linguistic, systematic, teleological, and arguments from intention (Komarek, 2015: 45). Linguistic arguments derive the meaning of a norm from the literal expression 
of the legal text. The function of the Court is to ensure that the provisions of the EU law are interpreted and applied uniformly in all the languages of the EU. Two tendencies appear in this situation - on the one hand, the equivalence of all linguistic expressions of judgments and, on the other hand, the uniformity of the meaning of the judgments. Moreover, the Court insists that EU law terminology is peculiar to the EU law. Legal terms do not necessarily have the same meaning in EU law and the law of the member states as formulated in the CILFIT case (named after the company involved in legal proceedings): 'legal concepts do not necessarily have the same meaning in community law and the law of the various member states' (Judgment 2). Interpretation of the EU law creates a supranational meaning. For example, in Sumitomo (Judgment 6) the Court says:

The meaning and scope of Article [...] emerge from an independent interpretation of that provision, carried out according to the literal, contextual, teleological and systematic methods of interpretation. Accordingly, there is no need to refer to the laws of the Member States in interpreting that provision.

If there is a conflict between different language versions of a norm, systemic and teleological arguments will be used, and they will be considered more relevant than linguistic arguments (Komarek, 2015: 45). Teleological interpretation refers to a systemic understanding of the EU legal order, which is the ultimate purpose serving as a means of interpretation and is predominant (Kaczorowska, 2011: 230; Paunio, 2013: 5, 42). In the Euro Tex case (named after the company involved in the legal proceedings) (Judgment 7), the Court says:

It is settled case-law that the different language versions of a Community text must be given a uniform interpretation and hence, in the case of divergence between the language versions, the provision in question must be interpreted by reference to the purpose and general scheme of the rules of which it forms a part.

Judgments give an interpretation on interpretation, i.e., they establish principles of how EU law should be interpreted. For example, the landmark CILFIT case formulates the acte clair doctrine - if a judgment or rule of law is clear enough, then the member state has no duty to refer the question for a preliminary ruling to the CJEU (Judgment 2). The CILFIT case also formulated the requirement to compare different language versions. In this aspect, the CJEU contradicts itself because it does not regularly compare different language versions, but only if the parties express such initiative (Bengoetxsea, 2011: 110).

In this paper, the judgments of CJEU are viewed as narratives. It is assumed that a narrative means 'any minimal linguistic act', any expression which communicates the message of the sender to the addressee using signs (language) (McQuillan, 2000: 10). Narrative makes sense by ensuring the communication 
process between the sender and the addressee of the message. Narrative analysis is an important tradition in discourse analysis. In this paper, it is necessary to keep in mind two related meanings of the term discourse. Firstly, according to the semiotic model of linguistic signs, the narrative consists of its story and discourse where the story is a sequence of events over time (the content plane of the narrative - events, the transition from one state to another), but discourse is the expression level - 'the how of the narrative as opposed to its what' (Prince, 1987: 21). Secondly, discourse is 'language above the sentence or above the clause' (Stubbs, 1983: 1).

Discourse analysis puts the text in a broader context and meaning to account not only for the way the text is constructed but also for the way it is interpreted and used in specific institutional and professional contexts to achieve specific disciplinary goals. Such understanding goes together with a broader approach to discourse as social practice and its interaction with a more extensive social context (Bhatia, 2012: 246-247). Judgments of the CJEU can only be read and interpreted in relation with the relevant legal acts in each case, which may be EU primary and secondary law, member state law, other case law judgments from the CJEU and other. It may be argued that these judgments should be read across the given text and by keeping other legal texts in mind.

Judgments of the Court do not look like stories in an ordinary sense; however, they can be looked upon as narratives where certain legal information is presented in an established formulaic manner. These are lengthy texts that look similar due to their complex syntactic structure. Within a judgment one can find the elements determined by Labov: abstract, orientation, complicating action, evaluation, result or resolution and coda (Labov, 2010: 2-4). The mentioned elements mostly coincide with the structural parts of a judgment - the header, keywords, summary, parties, subject of the case, grounds, decision on costs, and operative part. In this paper, these sections are called macrostructures - visibly separate and relatively independent parts. Van Dijk calls a macrostructure a unit larger than one sentence, which in the text has significance as a whole and is a relatively independent unit. Very large textual structures like the whole text are superstructures. All structures can be divided into thematic (semantic) and textual grammar (syntactic) macro-structures (Van Dijk, 1976: 548). Van Dijk considers that 'schematic superstructures organize thematic macrostructures, much in the same way as the syntax of a sentence organizes the meaning of a sentence' (Van Dijk, 1985: 69).

Van Dijk has found that 'macrostructures are involved in our ability to summarize stories' (Van Dijk, 1976: 547). The finding that interpretation and summarising processes are connected to macrostructures is particularly important for the reading of judgments. Based on understanding of macrostructures, certain strategies or rules can be formulated to interpret these long texts drafted in difficult language. Van Dijk points out the hypothetical character of such an approach and calls it 'expedient interpretation strategy' 
(ibid.: 549). To understand, memorize, keep them in memory and recall stories, a model is necessary - 'a set of macro-rules, which determine our interpretation of a discourse at a level superior to that of sentence and sequence comprehension, and which explains how and which information can be integrated into higher order propositions' (ibid.).

\section{METHODS}

The study takes a qualitative approach to the selected judgments, where the CJEU interprets EU law and previous judgments connected with multilingual reasoning and interpretation of legal texts in the EU multilingual situation. The judgments are of various length and complexity; they cover the period from 1963 to 2006 and all are landmark cases, i.e., important cases that will establish new laws and set new precedents.

Legal reasoning and interpretation in this study is the question about reception of legal text as far as it deals with the literal method of interpretation of the law, apart from the teleological approach, which is also taken into account.

The frame for this study was developed from the semiotic method which is a communicative approach and sees a text as a message sent by the Court to the recipient. The message sent by the Court is a specific type of narrative. The text of the selected narratives was studied closely - each judgment as a whole, as a separate independent text with its beginning, middle and end, as well as the judgments were read by separating their texts into the macrostructures and paragraphs. Then the syntactic and semantic role of each macrostructure and paragraph was evaluated applying the theoretical instruments described by Van Dijk (1976, 1985) and Labov (2010). Subsequently, the basic structure of judgments was drawn and compared and the findings of the narrative structure of the judgments were described, taking into account their interpretation possibilities.

\section{RESULTS AND DISCUSSION}

For this research, seven judgments in English were selected, in which the Court, among other issues, deals with the linguistic aspect of legal interpretation. The English of these judgments is not that of the UK and common law. It is the language of the official communication, one of the pivot languages and working languages of EU institutions. The languages of the procedure of the selected judgments are Italian, German, Spanish, and English and Dutch in two cases each. The English version of the judgments carries multilingual character due to the presence of other official EU languages. For example, the case of Marleasing (Spanish), the Spanish court, the names of the parties in the main proceedings are mentioned in Spanish; a judgment in German is quoted by the CJEU.

Judgments take the form of embedded narrative - the core narrative and framing narrative. Such narrative structure of a judgment is determined by 
the meaning of preliminary ruling - a decision of the CJEU on the interpretation of European Union law, given at the request of a court of an EU member state. The domestic court proceedings are adjourned until the CJEU ruling is issued. Therefore, the core narrative is the story of the main proceedings and how the domestic court formulated the question/s to the Court.

In Euro Textilverwertung $\mathrm{GmbH}$ case (hereinafter Euro Tex), the core narrative is included in paragraphs 9 to 17 of the Grounds. The Euro Tex company managed a certified undertaking which collected, transported and processed clothes and textiles. In 1998 and 1999, Euro Tex delivered textiles to retailers in Poland; they attached the declarations of origin of the goods to their invoices. After an inspection at Euro Tex's premises, the Hauptzollamt Duisburg (principal customs administration, hereinafter the Hauptzollamt) declared that Euro Tex could not prove the origin of the goods. The German authorities withdrew the certificates and stated that they would inform the Polish authorities of the results of the inspection. Euro Tex made a complaint about that decision to the Hauptzollamt, which rejected the complaint as unfounded. The Hauptzollamt also concluded that the conditions referred to by Protocol 4 for the used textiles were not fulfilled. The decision stated that the sorting and matching operations carried out, in this case, constituted no more than minimal processing which did not affect the origin of the products. Euro Tex then brought proceedings before the Finanzgericht (financial court) Düsseldorf. Uncertain as to the interpretation of Article 7(1) (b) of Protocol 4, the Finanzgericht Düsseldorf decided to stay the proceedings and to refer the question to the CJEU for a preliminary ruling: 'Do the matching operations [...] go beyond simple operations of matching for Article 7(1) (b) of Protocol 4?' The uncertainty of the Finanzgericht Düsseldorf arises from differences between several language versions of Protocol 4 . The main issue before the Court is more abstract - the correctness of the proofs of origin provided for the export of used textiles. The answer given to the question from the member state court is that no distinction between simple and more complex matching operations can be drawn.

The framing narrative gives the interpretation of the question asked and the clarification of the uncertainties caused by language differences. The facts of the case are placed within the legal discourse and appear detached from the reallife events. The core narrative is reduced to abstract concepts and the real case and its facts are dissolved and turned into abstract legal narrative alongside with many similar cases, which lose their original character and since that moment serves as a means for interpretation of a certain legal norm. The framing narrative of the judgment is marked by intertextuality of legal texts and repetitions. In the Euro Tex judgment, Article 7(1) (b) of Protocol 4, the Kyoto Convention, and several cases from the EU case law have contributed to the intertextuality of the judgment. Besides, the framing narrative is interwoven with argumentation from the mentioned legal acts and case law. The authoritative voice of the Court makes sense of the narrative and explains its meaning in the grounds and arrives at the interpretation of the legal norm, i.e., answers the question asked 
by the domestic court. The Court is the master narrator with a hermeneutic role, because it gives the definitive interpretation in preliminary cases, and it intervenes to give the definitive resolution in appeals and annulment cases.

The judgments of the CJEU consist of the same syntactical units. A judgment starts with the Header which consists of the CELEX number and brief information about the case. All legal documents have their unique CELEX numbers - small but informative macro-structures consisting of numbers and letters. The CELEX numbers of case law judgments start with the digit 6 which denotes the sector of law - case law. The initial digit is followed by the year when the case was entered the Court's register. For example, in the Marleasing case (Judgment 3) with CELEX number 61989J0106, the year is 1989. The letter in the centre of the CELEX number is J indicating the document type - judgment. The final digits denote the case number. The rest of the header gives very general information about the case - the parties, the type of legal area of the Court, the relevant EU legislation. All this information is given in the form of enumeration, but not a sentence, each important item separated from another by a full stop and a dash (or only a dash in more recent judgments).

61989J0106

Judgment of the Court (Sixth Chamber) of 13 November 1990. Marleasing SA v La Comercial Internacional de Alimentacion SA. - Reference for a preliminary ruling: Juzgado de Primera Instancia e Instruccion no 1 de Oviedo - Spain. - Directive 68/151/ CEE - Article 11 - Consistent interpretation of national law. - Case C-106/89. (Judgment 3)

Like the header, Keywords is an enumeration of words and phrases - legal concepts relevant to the case and the legal acts where the latter are mentioned more precisely in keywords than in the header. The list of concepts and legislation is structured in paragraphs.

The keywords are followed by the Summary consisting of numbered paragraphs and expressed in sentences which are usually rather long and complex. For example, in the Marleasing case (Judgment 3), the summary consists of two paragraphs of two sentences each, the word count 130 and 167 in the first and second paragraphs respectively. The summary gives the interpretation of the relevant law, not the summary of the facts of the case. If the judgment is a preliminary ruling, the interpretation of EU legislation is repeated in other syntactical macro-structures - the Grounds and the Operative part. Between the summary and the grounds, there are Parties and Subject of the case. Sometimes the subject of the case is omitted because it can be inferred from the header. The grounds is the longest macro-structure and the most complicated, consisting of many paragraphs which may be grouped in sub-structures like in Van Gend and Loos (Judgment 1), EMU Tabac (Judgment 4), KIK (Judgment 5), Sumitomo (Judgment 6), or Euro Tex (Judgment 7). The grounds start with the facts of the case. If the judgment is a preliminary ruling, the question/s 
before the Court are formulated, discussed and answered. If the judgment is an action against a member state or an EU institution, the parties give their arguments, first the applicant and then the defendant. After the arguments of the parties, the Court gives the legal grounds and the decision. The final macrostructures of any judgment are Decision on costs and Operative part which speak for themselves - which party pays the costs and the decision of the Court.

To disclose the correspondence between the syntactic and semantic macrostructures here follows a brief discussion of one of the judgments. KIK (Judgment 5) consists of the following macrostructures: the summary and the judgment. The summary has its header, keywords and the summary which is made up of four paragraphs and gives the interpretation of the EU law in this appeals case and the answer to the decision of the Court of First Instance (CFI) to dismiss the appeal. The judgment has a separate header, the parties to the case, and the judgment. The introductory paragraph states that Ms Kik brought an appeal against the judgment in which the CFI dismissed her application for annulment of the decision of the Office for Harmonisation in the Internal Market (OHIM) dismissing her appeal against the examiner's refusal to register the word KIK as a Community trademark. Paragraphs 2 to 8 deal with the legal background of the case. First, the Community rules for language are explained and the official and working languages at that time (2003) are listed. Documents that a member state or a person of a member state sends to institutions of the Community may be drafted in any of the official languages and the reply must be drafted in the same language. Paragraph 7 states that the application for a Community trademark must be filed in one of the official languages and a language of the OHIM must be indicated Paragraph 9 gives the background to the dispute which is set out in a number of subparagraphs. It says that the applicant submitted an application to register trademark under name KIK. The application was in Dutch, which was also indicated as a second language. The examiner dismissed the application on the ground that a second language was not indicated. The applicant brought an appeal against that decision in Dutch and English. The appeal was dismissed by the Board of Appeal of the OHIM. The judgment continues with the proceedings before the Court of First Instance and the contested judgment - paragraphs 10 to 18. In this section, the proceedings are described. Paragraphs 19 to 24 deal with the procedure before the Court of Justice and forms of order sought where it is said that the appellant meanwhile has died but her heirs and beneficiaries are determined to continue to appeal requesting the contested judgment (CFI) to be set aside, the forms of order sought at first instance be upheld and that the OHIM be ordered to pay the costs of the first instance and appeal proceedings. Finally, there comes the appeal (paragraphs 25 to 105) which contains two large substructures of text - arguments of the parties (paragraphs 25 to 37) and findings of the Court (paragraphs 38 to 105). The Court gives the interpretation of the EU law on the language regime in the given case. The interpretation is the legal grounds on which the appeal is dismissed by the Court and the losing party is ordered to pay the costs. This interpretation is given in the summary part of the judgment. 
The KIK case is difficult to read, remember and summarise the facts, the law and the reasoning of the court. The whole text of the judgment is a superstructure consisting of macro-structures and sub-structures in several levels. Such complexity may be intimidating to the reader. Other structurally more complicated judgments are Van Gend and Loos, EMU Tabac, Sumitomo and Euro Tex. Their narrative structure displays dialogism where communication takes place between a domestic court and the CJEU if it is a preliminary ruling, or communication between an applicant (or an appellant) and the CJEU if it is an action against an EU institution.

\section{CONCLUSIONS}

The structure of judgments is immediately obvious from the layout of the text all judgments consist of the main macro-structures: a header, keywords, a summary, parties, the subject of the case, the grounds, the decision on costs and the operative part. Each separate judgment, which is a superstructure, in this case, reproduces such form in all forthcoming judgments. Some shorter and structurally simpler judgments have only the mentioned macro-structures, while longer and more complex judgment texts develop a more hierarchical structure within the grounds or summary to include core narratives. According to the narrative elements defined by Labov (2010: 2-4), each macro-structure has its purpose: the header, keywords and the summary of the judgment provide the abstract of the narrative; the facts of the case given at the beginning of the grounds is the orientation of the narrative; the legal issue or questions brought before court serve as complication of the action; evaluation of the message appears in the form of discussion of the arguments of the parties according to the relevant legislation; answers to all the questions before court result in the resolution of the case; finally, the coda of the narrative is the decision and the operative part.

As a text type the judgments of the CJEU are marked by a high level of redundancy - repetition of the previously mentioned information. Judgments repeat the form and content to be interpreted in the correct meaning, not a range of different meanings. This surplus of reiteration is the narrative structure of judgments, which is the same or very similar in all texts. Preliminary rulings are especially reiterative - the same wording can be conveyed by two or three paragraphs of the judgment. Thus, the semantic and syntactic macro-structures may coincide or be different; the number of syntactic macro-structures prevails over that of semantic structures because a semantic structure may be represented by two or more syntactic structures.

Teleological reasoning carries more information about the content of law than textual interpretation. That is why a reader, who is more knowledgeable in the legal system of the EU, as well as its historical and political background, will be faster and more efficient. For every reader, including those with less experience in interpretation of judgments, starts with the literal, ordinary 
expression of the text. It is helpful that the reader is aware of the formal structure of judgments because it carries much of the meaning of the text. It can be argued that the narrative structure turns into an instrument for a better and faster getting the meaning from the text. The narrative structure is also a means of summarising the judgment and memorising the main points.

From the study of the selected judgments and theoretical sources described in this paper, it can be concluded that in a situation where narratives are many and different, e.g. different language versions, they reflect the European legal language that cannot be confined within the limits of one large coherent master narrative. Therefore, the wholeness or integrity must be imposed from the outside - by acknowledging the idea of such integrity. When the literal interpretation of legal texts fails because of language uncertainties, other legal interpretation methods step in, especially the teleological approach, which provides an abstract wholeness for the texts that otherwise differ. When such wholeness is created, the old hermeneutic principle can be applied - the interpretation hypothesis referred to one part of that wholeness must be valid for the full body of the relevant judgments or other legal texts. The impersonal, difficult and vague language of EU documents is the universal language of the EU because it is the communicative system of the EU, in spite of its 24 linguistic forms and 28 different legal cultures. Indeed, the EU multilingualism looks like some kind of controlled chaos, a model structured so that it preserves the complexity and contradiction of the reality as much as possible, however, controlled by the official discourse, legislation and case law.

\section{REFERENCES}

Bengoetxea, J. (2011) Multilingual and multicultural reasoning: the European Court of Justice. In S. Adamo and A. L. Kjær (eds.) Linguistic Diversity and European Democracy (pp. 97-122). Aldershot: Ashgate Publishing.

Bhatia, V. (2012) Professional written genres. In P. J. Gee and M. Handford (eds.) The Routledge Handbook of Discourse Analysis. London and New York: Routledge.

Breeze, R. (2013) Traversing legal narratives. In C. S. Guinda and M. Gotti (eds.) Narratives in Academic and Professional Genres (pp. 343-362). Bern: Peter Lang.

Campos-Pardillos, M. A. (2010) Going beyond the obvious in English for legal purposes: a few remarks on international legal English as a lingua franca in Europe. In R. C. Jimenez and A. L. Lopez (eds.) English in the European Context: The EHEA Challenge (pp. 175-195). Bern: Peter Lang.

Eco, U. (1997) The Search for the Perfect Language. London: Fontana Press.

Kaczorovska, A. (2011) European Union Law. $2^{\text {nd }}$ ed. London and New York: Routledge.

Komarek, J. (2015) Legal reasoning in EU law. In A. Arnull and D. Chalmers (eds.) The Oxford Handbook of European Union Law (pp. 28-51). Oxford: Oxford University Press.

Koskinen, K. (2000) Beyond Ambivalence. Postmodernity and the Ethics of Translation. Tampere: Tampereen yliopistopaino.

Labov, W. (2010) Uncovering the event structure of narrative. In D. Schiffrin, A. De Fina and A. Nylund (eds.) Georgetown University Round Table on Languages and Linguistics (2008): Telling stories: language, narrative, and social life (pp. 1-22). Washington, DC: Georgetown University Press. 
McAuliffe, K. and Trklja, A. (2018) Superdiversity and the relationship between law, language and translation in a supranational legal order. In A. Creese and A. Blackledge (eds.) Routledge Handbook of Language and Superdiversity (pp.461-477). London and New York: Routledge.

McAuliffe, K. (2013) The limitations of a multilingual legal system. International Journal for the Semiotics of Law, 26 (4): 861-882.

McAuliffe, K. (2012) Language and law in the European Union: the multilingual jurisprudence of the ECJ. In L. M. Solan and P. M. Tiersma (eds.) The Oxford Handbook of Language and Law (pp. 200-216). Oxford: Oxford University Press.

McAuliffe, K. (2011a) Hybrid texts and uniform law? The multilingual case law of the Court of Justice of the European Union. International Journal for the Semiotics of Law, 24 (1): 97-115.

McAuliffe, K. (2011b) Precedent at the Court of Justice of the European Union: the linguistic aspect. In M. Freeman and F. Smith (eds.) Law and Language. Current Legal Issues 2011, Vol. 15. (pp. 483-492). Oxford: Oxford University Press.

McAuliffe, K. (2010) Language and the institutional dynamics of the Court of Justice of the European Communities: lawyer-linguists and the production of a multilingual jurisprudence. In M. L. Gueldry (ed.) How Globalising Professions Deal with National Languages: Studies in Cultural Conflict and Cooperation (pp. 239-263). Lewiston, and New York: Edwin Mellen Press.

McQuillan, M. (ed.) (2000) The Narrative Reader. London and New York: Routledge.

Paunio, E. (2013) Legal Certainty in Multilingual EU Law: Language, Discourse and Reasoning at the European Court of Justice. Aldershot: Ashgate Publishing.

Prince, G. (1987) Dictionary of Narratology. Lincoln and London: University of Nebraska Press.

Robertson, C. (2014) EU legislative texts and translation. In L. Cheng and K. K. Sin (eds.) The Ashgate Handbook of Legal Translation (pp. 155-175). London and New York: Routledge.

Šarčevic, S. (2010) Creating a Pan-European legal language. In C. Williams and M. Gotti (eds.) Legal Discourse Across Languages and Cultures (pp. 23-50). Bern: Peter Lang.

Stubbs, M. (1983) Discourse Analysis. Oxford: Blackwell.

van Dijk, T. A. (1976) Narrative macro-structures. Logical and cognitive foundations. PTL: A Journal for Descriptive Poetics and Theory of Literature. 1 (1976): 547-568.

van Dijk, T. A. (1985) Structures of news in the press. In T. A. van Dijk (ed.) Discourse and Communication. New Approaches to the Analysis of Mass Media (pp. 69-93). Berlin: De Gruyter.

\section{ONLINE SOURCES}

[Online 1] Available from https://ec.europa.eu/education/policy/\%E2\%80\%8Bmultilingu alism/\%E2\%80\%8Blinguistic-\%E2\%80\%8Bdiversity_en [Accessed on 12 November 2019].

[Online 2] Available from http://www.europarl.europa.eu/thinktank/en/document.html? reference=EPRS_BRI(2017)595914 [Accessed on 12 November 2019].

[Online 3] Available from https://www.openaccessgovernment.org/law-and-language-multilingual-eu-law/55829/ [Accessed on 12 November 2019].

\section{SOURCES ANALYSED}

[Judgment 1] Van Gen den Loos - Case C-26/62 - NV Algemene Transport - en Expeditie Onderneming van Gend \& Loos $v$ Netherlands Inland Revenue Administration. Available from https://eur-lex.europa.eu/legal-content/EN/TXT/?uri=CELEX\%3A61962CJ0026 [Accessed on 25 August 2019]. 
[Judgment 2] Case C-283/81 - Srl CILFIT and Lanificio di Gavardo SpA v Ministry of Health. Available from https://eur-lex.europa.eu/LexUriServ/LexUriServ.do?uri=CELEX:61981 CJ0283:EN:HTML [Accessed on 25 August 2019].

[Judgment 3] Case C-106/89 - Marleasing SA v La Comercial Internacional de Alimentacion SA. Available from https://eur-lex.europa.eu/LexUriServ/LexUriServ.do?uri=CELEX:61989 CJ0106:EN:HTML [Accessed on 25 August 2019].

[Judgment 4] Case C-296/95 The Quee.n v Commissioners of Customs and Excise, ex parte EMU Tabac SARL, The Man in Black Ltd, John Cunningham. Available from https://eur-lex. europa.eu/legal-content/EN/TXT/HTML/?isOldUri=true\&uri=CELEX:61995CJ0296 [Accessed on 25 August 2019].

[Judgment 5] KIK v OHIM - Case C-361/01 P - Christina Kik v Office for Harmonisation in the Internal Market (Trade Marks and Designs) (OHIM). Available from https://eur-lex. europa.eu/legal-content/EN/TXT/?qid=1565510307490\&uri=CELEX:62001CJ0361 [Accessed on 25 August 2019].

[Judgment 6] Joined Cases T-22/02 and T-23/02 Sumitomo Chemical Co. Ltd and Sumika Fine Chemicals Co. Ltd v Commission of the European Communities. Available from https://eurlex.europa.eu/legal-content/EN/SUM/?uri=CELEX\%3A62002TJ0022 [Accessed on 25 August 2019].

[Judgment 7] Case C-56/06 - Euro Tex Textilverwertung GmbH v Hauptzollamt Duisburg. Available from https://eur-lex.europa.eu/legal-content/EN/TXT/HTML/?uri=CELEX: 62006CJ0056\&from=LV [Accessed on 25 August 2019].

Laimdota Ločmele (Assistant Prof., Dr. philol.) is currently working at the University of Latvia. Her research interests include Applied Linguistics, ESP, semiotics and discourse studies. Email: laimdota.locmele@lu.lv 